\title{
About the Royal Society of Chemistry
}

The Royal Society of Chemistry is the world's leading chemistry community, advancing excellence in the chemical sciences. With over 48,000 members and a knowledge business that spans the globe, we are the UK's professional body for chemical scientists, supporting and representing our members and bringing together chemical scientists from all over the world.

A not-for-profit organisation with a heritage that spans 170 years, we have an ambitious international vision for the future. Around the world, we invest in educating future generations of scientists to raise and maintain standards. We partner with industry and academia, promoting research excellence, collaboration and innovation. We advise government on policy. And we promote the talent, information and ideas that lead to great advances in science. In a complex and changing world, chemistry and the chemical sciences have an essential role to play. They will be vital in helping the world respond to some of its biggest challenges. We're working to shape the future of the chemical sciences - for the benefit of science and humanity.

The RSC Divisions and Interest Groups play an important role in contributing to the many RSC activities in support of the chemical sciences. The Organic Division currently has 8,700 members based in industry and education from around the world. Its main objective is to encourage and promote advances in the field of organic chemistry. In particular, the Organic Division stimulates and supports many local, national and international meetings, symposia and conferences on topics of interest to organic chemists. The Organic Division was delighted to support the RSC/BMOS Young Investigator Award in collaboration with the Organic group of the Brazilian Chemical Society (SBQ). Five excellent candidates have selected and will present their work at this conference.

The Division also bestows awards every year, they also actively promote chemistry to the general public and offer advice on RSC publications and policy documents relevant to their subject. Please visit the Organic Division website at www.rsc.org/organicdivision

The Royal Society of Chemistry has an office in Brazil based in Sao Paulo. Dr Elizabeth Magalhaes is the RSC Brazil Manager and is happy to answer your queries about any aspects of the Royal Society of Chemistry including its activities in Brazil, its membership services and publishing activities.

We hope that you enjoy this conference featuring internationally leading scientists.

Elizabeth Magalhaes

Manager, RSC Brazil

<magalhaese@rsc.org>
Ray Jones

Organic Division Council President 